\title{
Disruption of IGF-1R signaling increases TRAIL-induced apoptosis: A new potential therapy for the treatment of melanoma
}

\author{
Thomas B. Karasic, Tom K. Hei, Vladimir N. Ivanov* \\ Center for Radiological Research, Department of Radiation Oncology, College of Physicians and Surgeons, Columbia University, New York, \\ NY 10032, USA
}

\section{A R T I C LE IN F O R M A T I O N}

Article Chronology:

Received 8 January 2010

Revised version received

1 April 2010

Accepted 15 April 2010

Available online 22 April 2010

\section{Keywords:}

IGF-1R

AKT

TRAIL

Apoptosis

Melanoma

\begin{abstract}
A B S T R A C T
Resistance of cancer cells to apoptosis is dependent on a balance of multiple genetic and epigenetic mechanisms, which up-regulate efficacy of the surviving growth factor-receptor signaling pathways and suppress death-receptor signaling pathways. The Insulin-like Growth Factor-1 Receptor (IGF-1R) signaling pathway is highly active in metastatic melanoma cells by mediating downstream activation of PI3K-AKT and MAPK pathways and controlling general cell survival and proliferation. In the present study, we used human melanoma lines with established genotypes that represented different phases of cancer development: radial-growth-phase WM35, vertical-growth-phase WM793, metastatic LU1205 and WM9 [1]. All these lines have normal NRAS. WM35, WM793, LU1205 and WM9 cells have mutated BRAF (V600E). WM35 and WM9 cells express normal PTEN, while in WM793 cells PTEN expression is down-regulated; finally, in LU1205 cells PTEN is inactivated by mutation. Cyclolignan picropodophyllin (PPP), a specific inhibitor of IGF-1R kinase activity, strongly down-regulated the basal levels of AKT activity in WM9 and in WM793 cells, modestly does so in LU1205, but has no effect on AKT activity in the early stage WM35 cells that are deficient in IGF-1R. In addition, PPP partially down-regulated the basal levels of active ERK1/2 in all lines used, highlighting the role of an alternative, non-BRAF pathway in MAPK activation. The final result of PPP treatment was an induction of apoptosis in WM793, WM9 and LU1205 melanoma cells. On the other hand, dose-dependent inhibition of IGF-1R kinase activity by PPP at a relatively narrow dose range (near $500 \mathrm{nM}$ ) has different effects on melanoma cells versus normal cells, inducing apoptosis in cancer cells and G2/M arrest of fibroblasts. To further enhance the pro-apoptotic effects of PPP on melanoma cells, we used a combined treatment of TNF-Related Apoptosis-Inducing Ligand (TRAIL) and PPP. This combination substantially increased death by apoptosis for WM793 and WM9 cells, but did so only modestly for LU1205 cells with very high basal activity of AKT. The ultimate goal of this direction of research is the discovery of a new treatment method for highly resistant human metastatic melanomas. Our findings provide the rationale for further preclinical evaluation of this novel treatment.
\end{abstract}

(c) 2010 Elsevier Inc. All rights reserved.

\footnotetext{
* Corresponding author. Center for Radiological Research, Columbia University, VC11-236, 630 West 168th Street, New York, NY 10032, USA. Fax: +1 2123053229

E-mail address: vni3@columbia.edu (V.N. Ivanov).

Abbreviations: AP-1, activator protein-1; DR4, death receptor-4; DR5, death receptor-5; EMSA, electrophoretic mobility shift assay; ERK, extracellular signal-regulated kinase; FACS, fluorescence-activated cell sorter; FasL, Fas ligand; I $k B$, inhibitor of NF-kB; IGF-1, insulin-like growth factor; IGF-1R, insulin-like growth factor receptor; IKK, inhibitor nuclear factor kappa B kinase; MAPK, mitogen-activated protein kinase; MEK, MAPK/ERK kinase; MFI, medium fluorescence intensity; NF-KB, nuclear factor kappa B; PI, propidium iodide; PPP, picropodophyllin; STAT, signal transducers and activators of transcription; TNF $\alpha$, tumor necrosis factor alpha; TRAIL, TNF-related apoptosis inducing ligand; TRAIL-R, TRAIL-Receptor
} 


\section{Introduction}

Melanoma, the deadliest form of skin cancer, is often markedly resistant to treatments using conventional radiotherapy or chemotherapy. Because of this widespread resistance, the metastatic stage of melanoma is almost incurable [2]. The U.S. Food and Drug Administration approved the only anti-metastatic melanoma drug, dacarbazine, in 1975. During the last two decades, enormous efforts have been undertaken to increase the effectiveness of cancer treatments, including those for metastatic melanoma, through the induction of programmed cell death by apoptosis [3]. TNF-Related Apoptosis Inducing Ligand (TRAIL) is particularly attractive for anti-cancer treatment due to its low toxicity and synergy with conventional cancer therapies $[4,5]$. While early clinical trials have found no single-agent activity of TRAIL in lung cancer [6], preclinical work has suggested that TRAIL may work synergistically with conventional therapies to improve cancer outcomes [7], and several clinical trials are currently underway testing this approach. Additionally, various methods have been used to sensitize cancer cells to TRAIL-induced apoptosis, with some promising results [8]. Most melanoma cells demonstrate resistance to TRAIL through multiple genetic and epigenetic mechanisms that suppress death signaling pathways and promote cell survival. Notably, PI3K-AKT, MEK-ERK, IKK-NF-KB, JAK2-STAT3 and ATM signaling pathways, which are critically involved in the regulation of cell proliferation, cell survival and protection against apoptosis, are often upregulated in metastatic melanoma cells and showed a marked propensity for preventing of cell death [9-11].

As with the various apoptosis activators such as TRAIL and Fas Ligand, the corresponding inhibitors of cell survival signaling pathways have been the subject of widespread study for cytostatic and anti-cancer activities. In previous studies, we and others demonstrated the relatively modest effects of small molecular inhibitors of the MEK-ERK and PI3K-AKT signaling pathways on the induction of apoptosis in human melanoma cells; in contrast, the combined targeting of both of these pathways resulted in substantial acceleration of cancer cell death [12,13]. Growth factor receptor kinase activity is an upstream regulator of the MEK-ERK and PI3K-AKT signaling pathways. The IGF-1 Receptor (IGF-1R)mediated signaling pathway is in the control of numerous functions in normal mammalian embryogenesis and postnatal development, tissue growth and general metabolism. Insulin and Insulin-like growth Factors (IGF-1/2), together with IGF-1 Receptor, have been increasingly shown to have important roles in neoplasia $[14,15]$. Cleavage and processing of the precursor pro-receptor (230 kDa) produces a $135 \mathrm{kDa} \alpha$-subunit and a $95 \mathrm{kDa}$ $\beta$-subunit. The IGF-1 Receptor complex contains two extracellular ligand binding $\alpha$-subunits and two $\beta$-subunits that contain an extracellular, a transmembrane, an intracellular tyrosine kinase and a C-terminal domain. IGF-1/IGF-2 binding induces autophosphorylation of IGF-1Rß, activation of its kinase activity and initiation of the downstream signaling cascades: N-RAS-B-RAF/C-RAF-MEKERK and PI3K-AKT-GSK3 $\beta$ or PI3K-AKT-mTOR [16].

IGF-1 is a critical factor for growth of many types of cancer, including melanomas, while inhibitors of IGF-1R-mediated signaling suppress the downstream PI3K-AKT and MAPK pathways, suggesting a strong pro-apoptotic activity for these inhibitors for some types of cancer $[17,18]$. However, as a result of Darwinian selection, many melanoma cell lines and original tumor samples possess signal activating mutations in transduction modules downstream to growth factor receptors, including the IGF-1 receptor, providing a partial autonomy from the growth factor stimulation. Activating mutations in NRAS are found in 33\% of primary and $26 \%$ of metastatic tumors, BRAF activating mutations were identified in a variety of melanoma cell lines and up to $67 \%$ of melanoma tumor samples [19,20]. Mutations in CRAF are relatively rare [21]. It is of note that $B R A F$ (V600E) and NRAS mutations are mutually exclusive in melanomas. On the other hand, PTEN, tumor suppressor and an inhibitor of the PI3K-AKT pathway is also mutated and inactivated in $20-40 \%$ of melanoma lines, but infrequently in the melanoma tumor samples, resulting in upregulation of the PI3K-AKT pathway [22]. BRAF and PTEN mutations are found concurrently in $20 \%$ of melanoma lines [23]. It should be highlighted that in spite of a partial independence of the MAPK pathway and the PI3K-AKT pathway from the upstream signaling in mutated melanoma lines, these cell lines often need certain level of growth factor (IGF-1/2, insulin, HGF or FGF2) stimulation via autocrine or paracrine mechanisms and a possible additional usage of the C-RAS bypass for effective growth [1].

Deregulation of these signaling pathways may occur not only through described mutations in NRAS, BRAF and PTEN, but also via up-regulation of expression levels and activation of IGF-1R, a characteristic feature of several types of tumors, including melanoma [15]. Multiple attempts were performed to suppress IGF-1R-mediated signaling in cancer cells using different approaches, including anti-sense RNA [24], siRNA [25], small molecular inhibitors [26] and antagonistic monoclonal antibodies [27]. Recently, drugs that block the signaling action of IGF family members have been found to have anti-tumor action [18,28,29]. Regulation of IGF-1R protein function through modification may occur not only by specific autophosphorylation, but also through SUMOylation and the nuclear translocation where modified IGF-1R plays a role for transcriptional regulation [30], demonstrating an alternative mechanism for IGF-1R to control carcinogenesis.

Melanoma cells do not express endogenous IGF-1/IGF-2 at notable levels, instead receiving these signaling ligands from fibroblasts in the microenvironment or through the bloodstream $[17,31]$. While the effects of both TRAIL agonists and IGF/IGF-1R antagonists are undergoing current clinical study separately, evidence linking their mechanisms for action suggests that they may act efficiently in combination to induce cell death. In other words, by blocking the actions of IGF-mediated survival signals, it may be possible to increase the efficacy of TRAIL and establish the induction of apoptosis as a more viable treatment pathway. Results of the present study indeed confirm the high efficacy of TRAIL and a IGF-1R-kinase inhibitor combination for killing human melanoma cells with low basal AKT activity (i.e. without complete inactivation of PTEN).

\section{Methods}

\section{Materials}

Cycloheximide (CHX) was obtained from Sigma (St. Louis, MO, USA). Human soluble Killer-TRAIL (recombinant) and human soluble Fas Ligand (recombinant) were purchased from Alexis (San Diego, CA, USA). IGF-1R kinase inhibitor picropodophyllin (PPP), PI3K inhibitor LY294002, MEK inhibitor U0126, MAPK p38 
inhibitor SB203580 and caspase inhibitor zVAD-fmk were purchased from Calbiochem (La Jolla, CA, USA).

\section{Cell lines}

Several human melanoma cell lines were used: WM35 is a radialgrowth-phase melanoma cells; WM793 is a vertical-growth-phase melanoma cells; LU1205 (also known as 1250lu) and WM9 are metastatic melanoma cells. All four melanoma lines have normal NRAS. WM35, WM793, LU1205 and WM9 cells have mutated BRAF (V600E). WM35 and WM9 express functional PTEN, while in WM793 cells PTEN expression is down-regulated; finally in LU1205 cells PTEN is inactivated by mutation $[1,21,32-35]$. Several human fibroblast lines were used: IMR-90, the primary human embryonic lung fibroblasts; TIG3, immortalized human embryonic lung fibroblasts; and HSF, human skin fibroblasts immortalized by SV40 T antigen. All cell lines, besides IMR-90, were maintained in DMEM medium, supplemented with $10 \%$ fetal bovine serum, L-glutamine and antibiotics. IMR-90 cells were maintained in medium supplemented with $15 \%$ fetal bovine serum, vitamins, non-essential amino acids and antibiotics.

\section{FACS analysis of TRAIL and TRAIL-R2/DR5 levels}

Surface levels of TRAIL-R1/DR4 and TRAIL-R2/DR5 on human melanomas were determined by staining with PE-conjugated antihuman DR4 or anti-human DR5 mAbs (eBioscience, San Diego, CA) and subsequent flow cytometry. PE-conjugated nonspecific mouse IgG1 was used as an immunoglobulin isotype control. A FacsCalibur flow cytometer (Becton Dickinson, Mountain View, CA) combined with the CellQuest program was used to perform flow cytometric analysis. All experiments were independently repeated 3-5 times.

\section{Apoptosis studies}

Cells were exposed to TRAIL ( $50 \mathrm{ng} / \mathrm{ml}$ ) alone, PPP (250 nM-2 $\mu \mathrm{M}$ ) alone, and a combination of TRAIL and PPP in order to determine the relative rates of apoptosis. Apoptosis was quantified as the percentage of hypodiploid (pre-G1) nuclei undergoing DNA fragmentation using PI staining and the flow cytometry (a FACS Calibur flow cytometer).

\section{Cell proliferation assay}

Cell were plated in six-well plates and allowed to attach for $24 \mathrm{~h}$ prior to the addition of DMSO or PPP to the culture medium (day 0 ). In some experiments, TRAIL was added to the culture medium after additional $24 \mathrm{~h}$ (day 1 ). Cell cultures were trypsinised and counted at day 0 , day 1 , day 2 and day 3 using a Coulter counter.

\section{Clonogenic survival assay}

Cells were exposed to soluble TRAIL $(50 \mathrm{ng} / \mathrm{ml})$ alone or in combination with CHX $(1 \mu \mathrm{g} / \mathrm{ml})$, PPP $(250 \mathrm{nM}-2 \mu \mathrm{M})$ alone or in combination with TRAIL for $24 \mathrm{~h}$. Treated cells (500/dish) were then placed in duplicate on 10 -cm dishes for analysis of clonogenic survival 12 days after treatment. Colonies were stained using crystal violet solution. The percentage of colony-formation (in relation to values for untreated control cells) was calculated.

\section{Western blot analysis}

Total cell lysates ( $50 \mu \mathrm{g}$ protein) were resolved on SDS-PAGE, and processed according to standard protocols. The monoclonal antibodies used for Western blotting included: anti- $\beta$-Actin (Sigma); anti-caspase-3; anti-ATM (D2E2) and anti-phospho-ATM (Ser1981); anti-phospho-IGF1-Receptor $\beta$ (Tyr1135/11360). The polyclonal antibodies used included: anti-phospho-SAPK/JNK (Thr183/Tyr185) and anti-JNK; anti-phospho-p44/p42 MAP kinase (Thr202/Tyr204) and anti-p44/p42 MAP kinase; anti-phospho-AKT (Ser473) and anti-AKT; anti-PARP; anti-STAT3, anti-phospho-STAT3 (Tyr705) and anti-phospho-STAT3 (Ser727); anti-IGF-1 receptor $\beta$ (Cell Signaling). The secondary Abs were conjugated to horseradish peroxidase; signals were detected using the ECL system (Amersham). Comparisons of the levels of the active phosphorylated proteins were made at several concentrations of PPP in order to elucidate the molecular pathway of its action.

\section{Statistical analysis}

Data was calculated using means and standard deviations. Comparisons of surviving fractions was made using Students' t-tests, with a p-value of 0.05 or less considered significant.

\section{Results}

\section{Inhibition of the cell signaling pathways in normal and melanoma cells by PPP}

The first aim of the present study was to evaluate effects of inhibition of the IGF-1R-mediated signaling pathway on the regulation of cell cycle arrest and apoptosis in human melanoma cell lines representing different phases of tumor development. We used WM35, a horizontal-growth-phase human melanoma line, WM793, a vertical-growth- phase human melanoma line, as well as LU1205 and WM9 human metastatic melanoma lines [36]. All four melanoma lines possess activating BRAF (V600E) mutation that results in up-regulation of the basal MEK-ERK1/2 activity. WM35 and WM9 cells express functional PTEN, while in WM793 cells PTEN expression is down-regulated; finally, in LU1205 cells PTEN is inactivated by mutation that was accompanied by a strong increase in the basal AKT activity [21,32-35,37]. Furthermore, we used as controls several human fibroblast lines: IMR-90, TIG-3 and HSF. Human melanoblasts, which required highly activating conditions for their growth in culture, could not be used as an adequate control for this type of experiment.

To further confirm a major role of IGF-1R-mediated signaling in the activation of the downstream AKT signaling pathways and in the regulation of cell cycle in human melanoma cells, we used picropodophyllin (PPP), a specific inhibitor of IGF1-R-mediated signaling that blocks the critical Tyr1135 autophosphorylation of the IGF-1-R $\beta$-subunit and suppresses its kinase activity [26]. Furthermore, prolonged treatment by PPP caused down-regulation of IGF-1R protein levels via its enhanced degradation [38]. IMR-90, human embryonic lung fibroblasts with non-detectable IGF-1R activation, did not specifically respond to PPP treatment $(0.5 \mu \mathrm{M})$. Very low levels of phospho-ERK, phospho-AKT, and phospho-GSK3 $\alpha$ were unchanged, and no growth arrest was observed for IMR-90 cells under these conditions (Figs. 1A and B), 
A

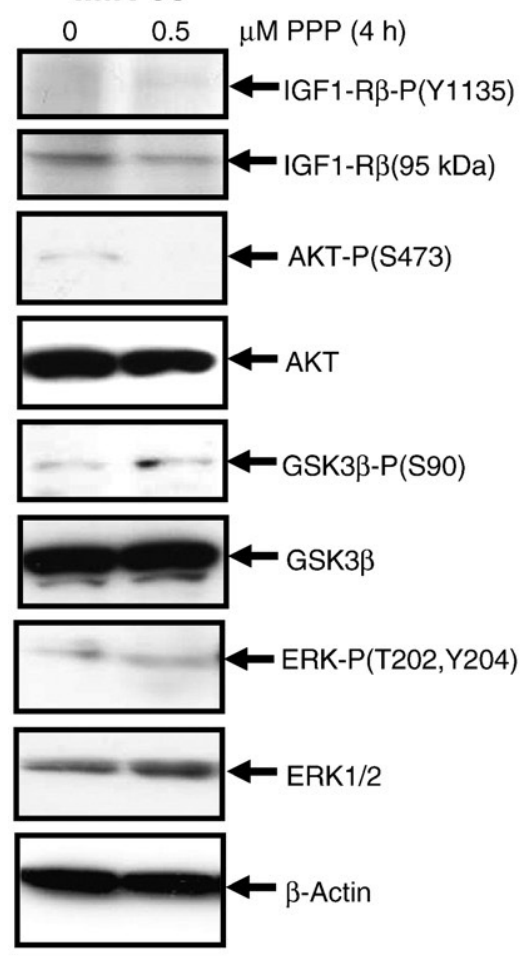

\section{HSF}
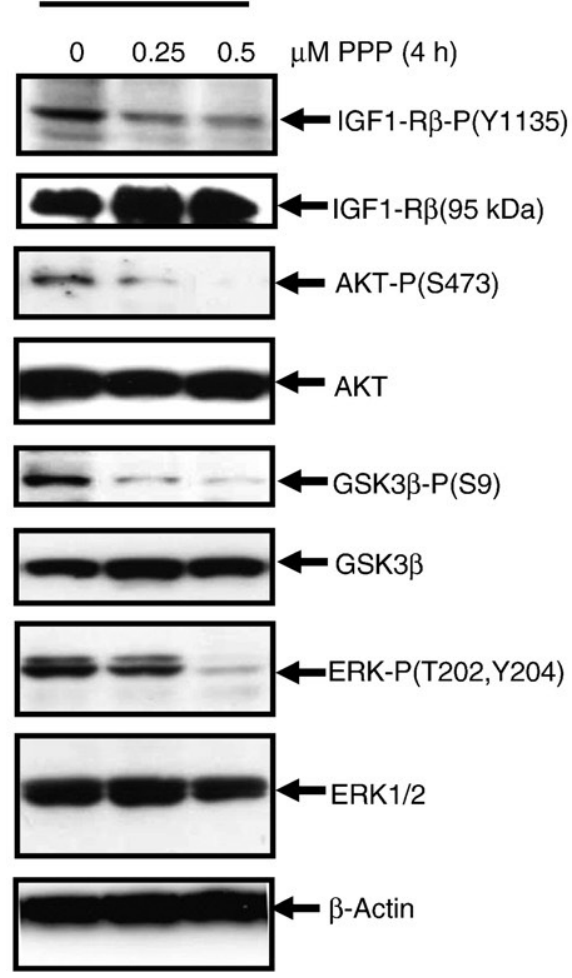

B
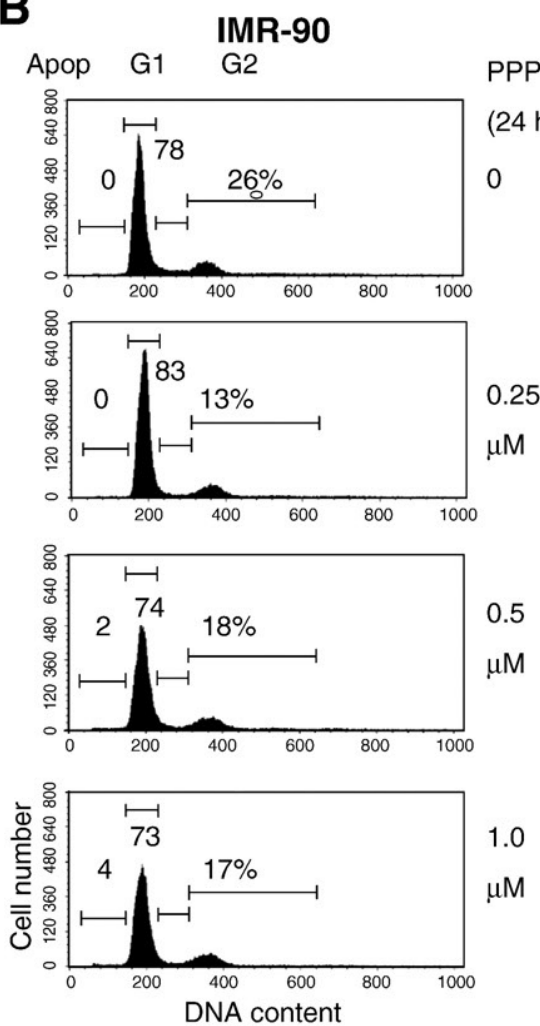

D

HSF
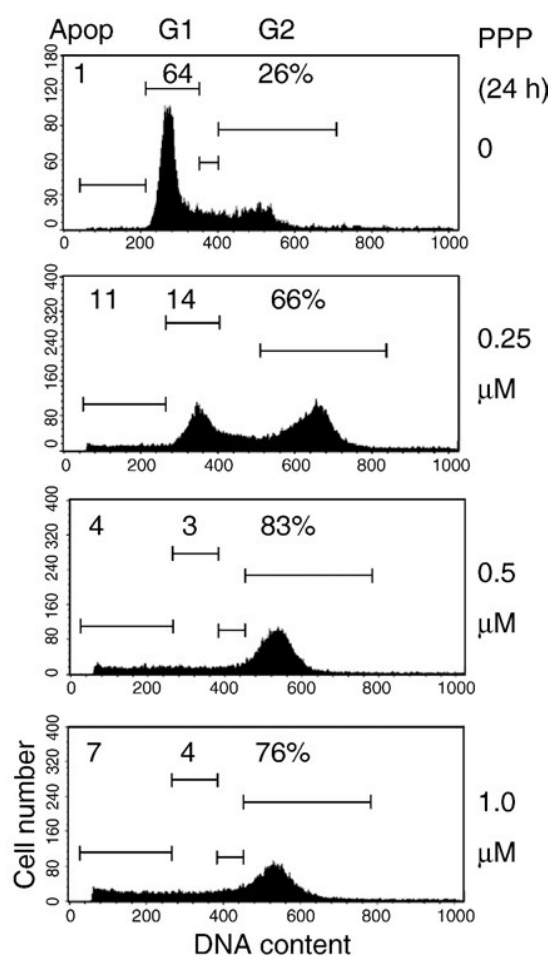

Fig. 1 - Effects of picropodophyllin (PPP) on IGF-1-mediated signaling pathway in human fibroblasts. A. Western blot analysis of indicated proteins $4 \mathrm{~h}$ after treatment of IMR-90 embryonic lung fibroblasts with PPP (0.5 $\mu \mathrm{M})$. B. Effects of PPP on cell cycle of IMR-90 $24 \mathrm{~h}$ after treatment. Cells were stained by PI $24 \mathrm{~h}$ after indicated treatment and analyzed by the flow cytometry. \% Cells at the distinct phases of the cell cycle is indicated. Results of typical experiments (one of four) are presented. C. Western blot analysis of indicated proteins $4 \mathrm{~h}$ after treatment of human skin fibroblasts (HSF) with PPP (0.25-0.5 $\mu \mathrm{M})$. D. Effects of PPP on cell cycle of HSF $24 \mathrm{~h}$ after treatment. 
while further cell proliferation was detected (data not shown). On the other hand, for the transformed human skin fibroblasts (HSF), down-regulation of IGF1-R kinase activity by $0.5 \mu \mathrm{M}$ PPP was accompanied by the expected decrease in the phosphorylation of AKT and its downstream target, GSK3 3 , and by the parallel decrease in phospho-ERK1/2 levels (Fig. 1C). Interestingly, PPP at doses 0.25 - $1 \mu \mathrm{M}$ PPP efficiently induced G2/M arrest of HSF $24 \mathrm{~h}$ after treatment (Fig. 1D).

Four hours after treatment, PPP $(0.5 \mu \mathrm{M})$ caused a strong decrease in phospho-(Tyr1135/1136) levels of both the precursor $(230 \mathrm{kDa})$ and the mature (95 kDa) $\beta$-subunit of the IGF-1 receptor in WM9 metastatic melanoma cells (Fig. 2A). In nontreated WM35 radial-growth-phase melanoma cells, IGF-1R was present mainly as the precursor form. Paradoxically, $0.5 \mu \mathrm{M}$ PPP induced an appearance of the mature $95 \mathrm{kDa} \beta$-subunit with some level of phosphorylation in these cells (Fig. 2A). As expected, an inhibition of IGF1-R kinase activity by PPP was accompanied by down-regulation of the levels of the active AKT-P-(Ser473) in WM9 cells. Furthermore, a partial down-regulation of ERK1/2-P(Thr202/Tyr204) levels was also observed (Fig. 2A). In contrast, for WM35 cells, $0.25-0.5 \mu \mathrm{M}$ PPP did not affect AKT activation, but still down-regulated ERK1/2 phosphorylation, highlighting a partial functionality of the IGF-1-induced signaling pathways in the early melanoma cells (Fig. 2A). A decrease in ERK1/2 phosphorylation levels by PPP in melanoma cells with activating BRAF (V600E) suggested the involvement of CRAF in ERK activation. WM9 cells, furthermore, possess notable basal levels of active MAPK p38, which were also strongly down-regulated by $0.5 \mu \mathrm{M}$ PPP $4 \mathrm{~h}$ after treatment (Fig. 2A).

A characteristic aspect of apoptotic commitment, caspase-3 activation via the cleavage of pro-caspase-3 (32 kDa), was detected in WM9 cells following PPP treatment, while the basal level of pro-caspase- 3 was very low in the WM35 early melanoma cells. The remarkable feature of the prolonged $24 \mathrm{~h}$ treatment with PPP was a caspase-mediated cleavage of ATM, an enzyme controlling numerous pro-survival and anti-apoptotic functions, in WM9 cells and dose-dependent down-regulation of ATM protein levels in the WM35 cells (Fig. 2B). In contrast, levels of anti-apoptotic proteins, Survivin and Smac, were relatively stable after PPP treatment (Fig. 2B). Hence, prolonged PPP treatment initiated apoptotic commitment in WM9 metastatic cells, but only suppressed some protein regulators of cell survival in WM35 early melanoma cells.

Down-regulation of the AKT activity by PPP was also observed in WM793 with intermediate levels of the basal AKT activity. In contrast, for LU1205 cells with increased levels of the basal AKT activity, due to PTEN inactivation, PPP at dose $0.5 \mu \mathrm{M}$ only modestly decreased AKT and ERK1/2 activities (Fig. 2C).

\section{Dose-response effects of PPP on inhibition of melanoma cell growth and induction of apoptosis}

Based on the functional specificity of PPP treatment, we determined its dose-dependent effects on cell cycle and growth of normal fibroblasts and melanoma cells in culture. We found that $0.5-2 \mu \mathrm{M}$ PPP efficiently induced $\mathrm{G} 2 / \mathrm{M}$ arrest of human skin fibroblasts (Fig. 1D) and TIG-3 fibroblasts (Fig. 3), while initiating apoptosis in WM793, LU1205 and WM9 melanoma cells in a dosedependent manner $24 \mathrm{~h}$ after treatment (Fig. 3). The early WM35 melanoma cells demonstrated a dual response: G2/M arrest at PPP
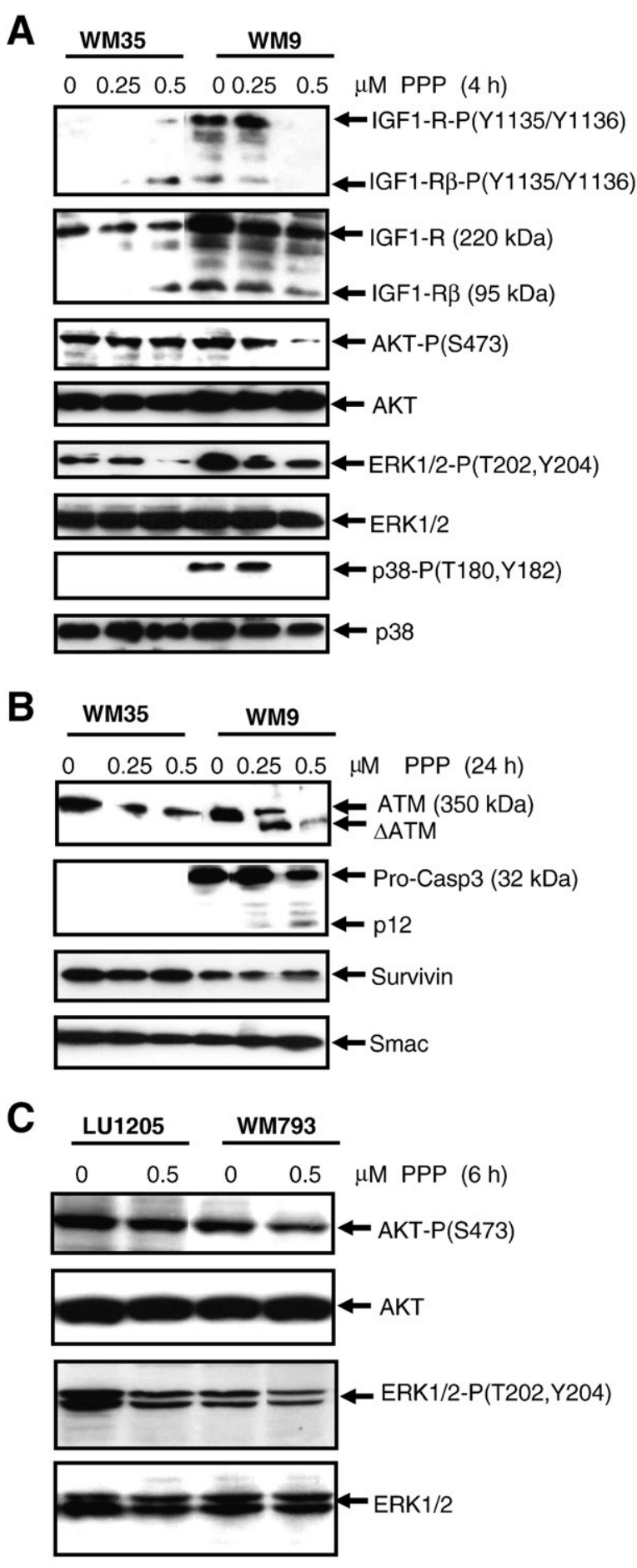

Fig. 2 - Effects of PPP on IGF-1-mediated signaling pathway in melanoma cells. A-C. Western blot analysis was performed 4-24 h after treatment of WM35 and WM9 or LU1205 and WM793 melanoma cells with indicated doses of PPP. Analyzed proteins are indicated.

a dose of $0.5-1 \mu \mathrm{M}$ and pronounced apoptosis with $2 \mu \mathrm{M}$ PPP $24 \mathrm{~h}$ after treatment (Fig. 3).

PPP at dose $0.5-1 \mu \mathrm{M}$ completely blocked growth of fibroblast and melanoma cell cultures (vertical-growth-phase WM793 and metastatic LU1205 and WM9 lines), with the exception of radial- 

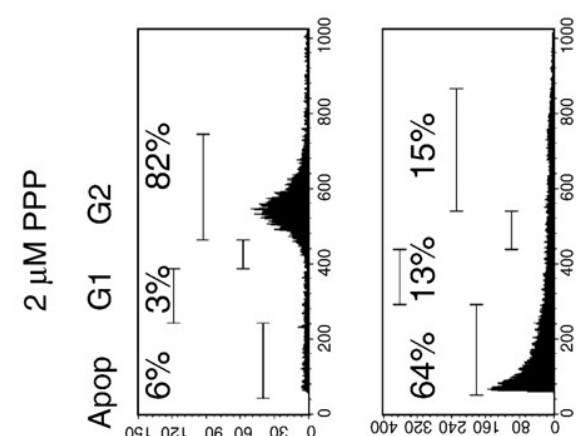

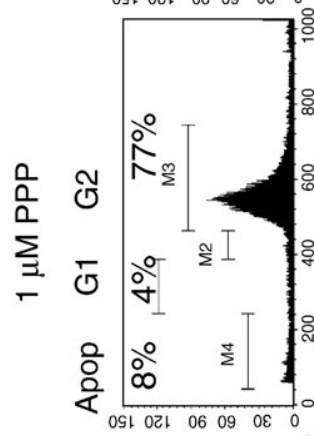
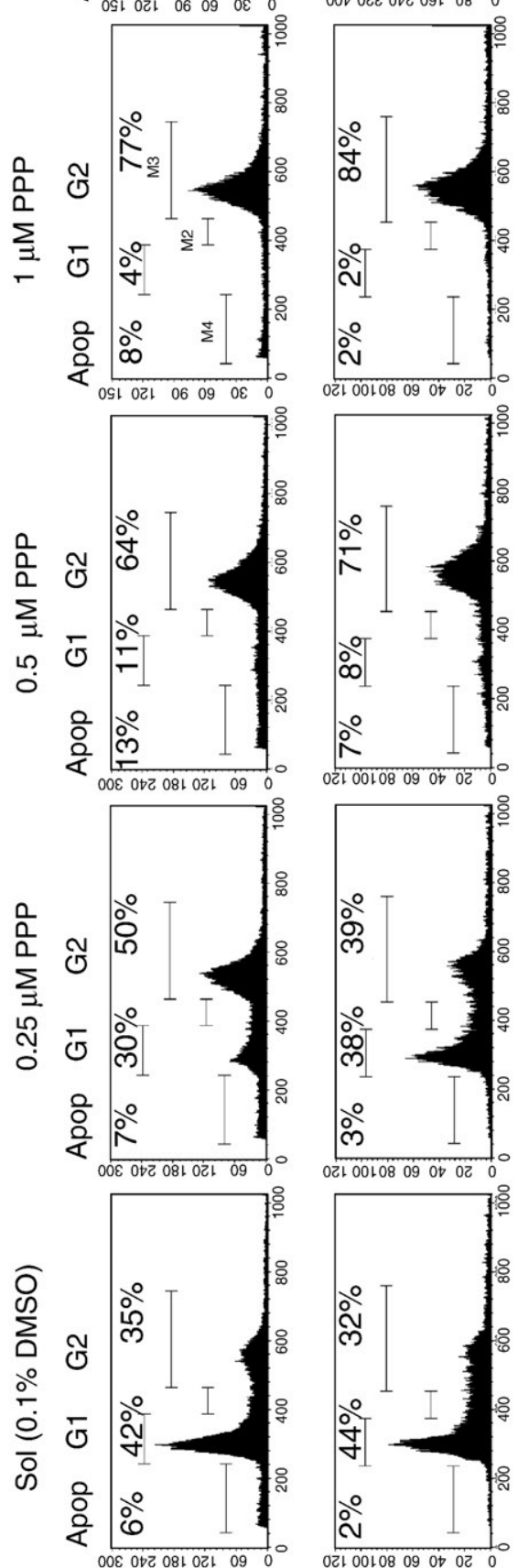

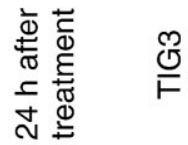
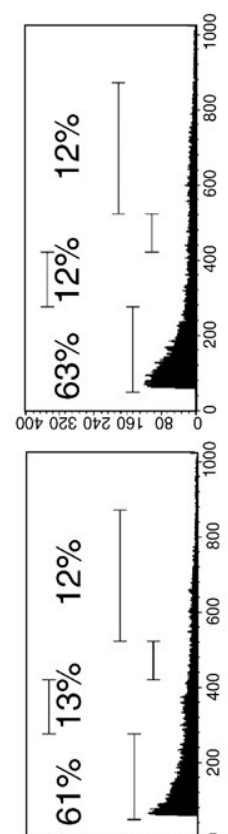

besente

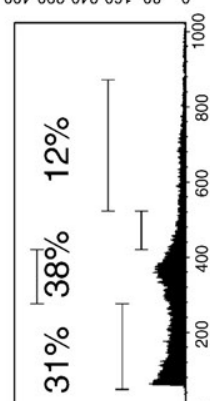

00t 0दह 0 कृ 091080
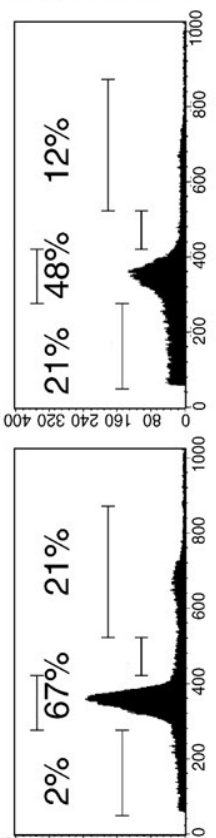

${ }_{0000} 082002091080$

$\sum_{3}^{N}$
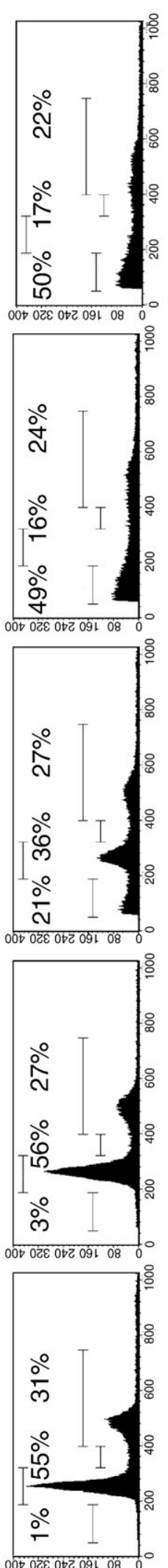

$\stackrel{\text { กิ }}{\frac{N}{5}}$

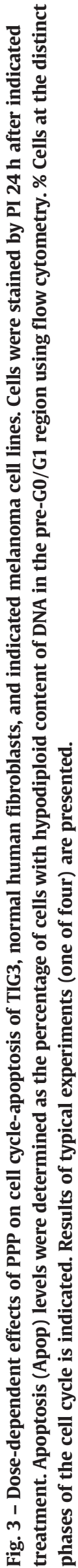


growth-phase WM35 melanoma cells, which required at least $2 \mu \mathrm{M}$ PPP for growth arrest (Fig. 4 and data not shown). Growth of IMR-90, normal embryonic lung fibroblasts with defective IGF-1Rmediated signaling, was not affected by PPP at the dose range of $0.5-2 \mu \mathrm{M}$ (Fig. 1B and data not shown).

\section{PPP decreases cellular survival in a dose-dependent manner}

Clonogenic survival assays after PPP treatment generally correlated with the cell cycle results measuring the induction of melanoma apoptosis, but also demonstrated non-apoptotic, probably, necrotic cell death for normal fibroblasts 12 days after treatment (Fig. 5). Values of total levels of cell death, however, indicated that the TIG-3 normal fibroblasts were more resistant to the $250 \mathrm{nM}$ and $500 \mathrm{nM}$ doses of PPP than were the melanoma cells (Fig. 5). HSF were modestly resistant to PPP ( $500 \mathrm{nM}-1 \mu \mathrm{M}$ ) compared to melanoma cells (data not shown). The primary IMR-90 fibroblasts, which demonstrated high resistance to PPP in the cell cycle analysis experiments (Fig. 1B), did not form colonies in the clonogenic survival assay. When combined with the cell cycle results, this narrow window of PPP doses near $500 \mathrm{nM}$ that had more pronounced negative effects on the survival of metastatic melanoma

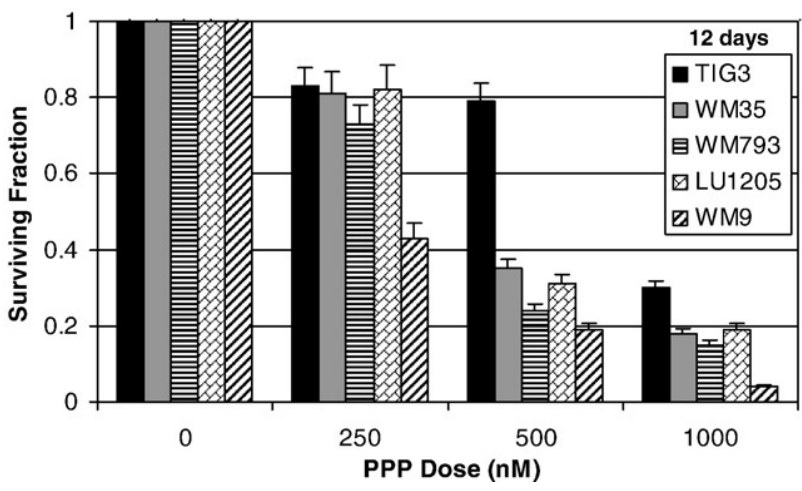

Fig. 5 - Clonogenic survival assay of fibroblasts and melanoma cell lines 12 days after treatment with PPP. Error bars represent mean \pm S.D. from three independent experiments (Student's $t$ test, $P<0.05$ ).

cells as compared to that of normal fibroblasts. WM9 melanoma cells demonstrated substantially higher sensitivity to PPP, compared to LU1205 cells with increased levels of AKT activity.

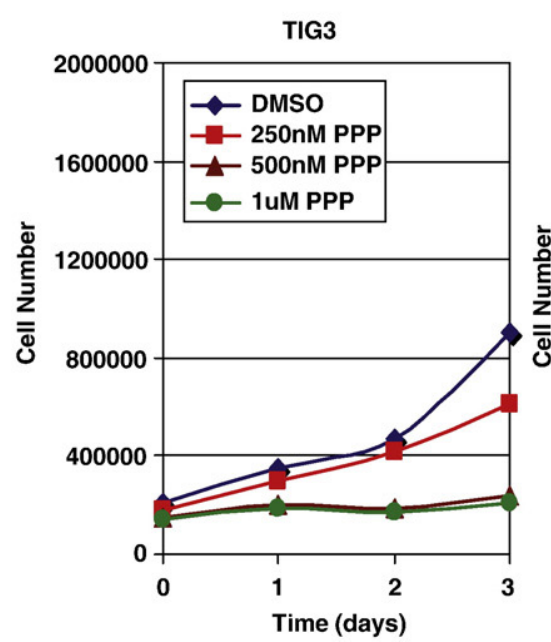

WM793

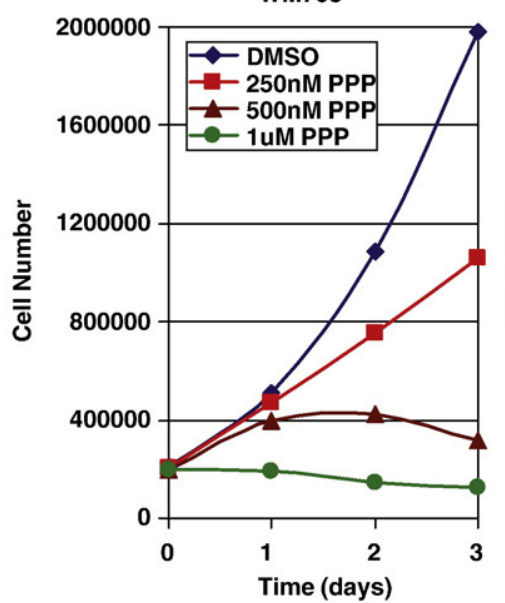

HSF

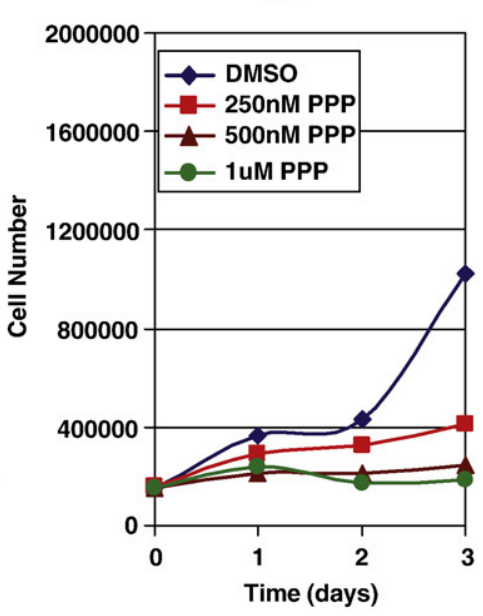

LU1205

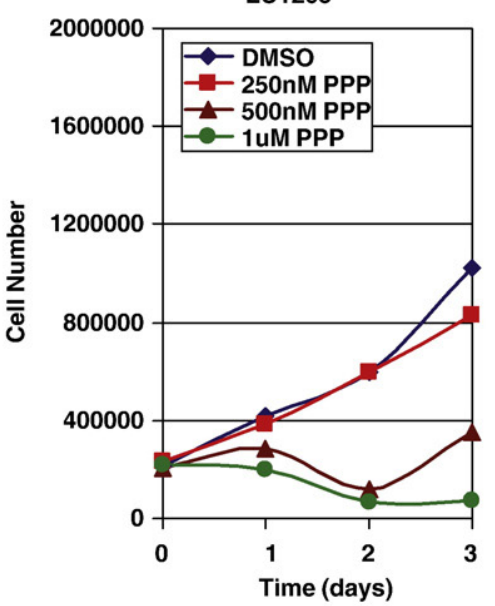

WM35

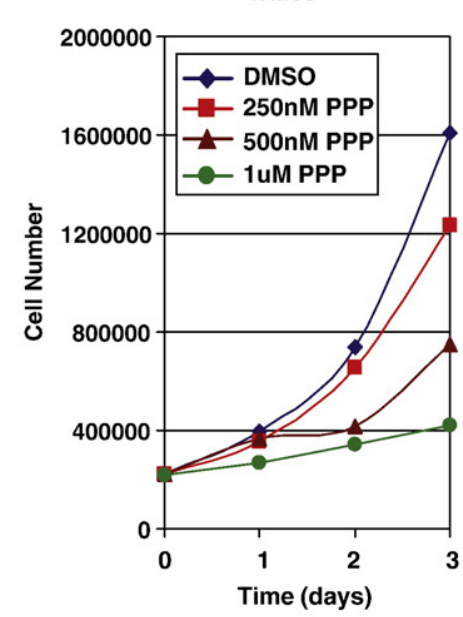

WM9

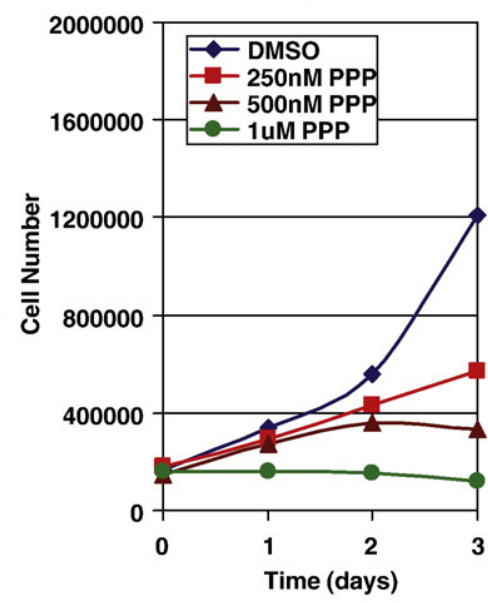

Fig. 4 - Dose-dependent effects of PPP on the cell growth of the normal (TIG3), transformed (HSF) and cancer (WM35, WM793, LU1205, WM9 melanoma) cell lines. PPP was dissolved in DMSO; the final concentration of DMSO in the medium was $0.1 \%$. 


\section{PPP sensitizes melanoma cells to TRAIL-mediated apoptosis}

The main objective for treatments that induce apoptosis in cancer cells is maximizing the specific killing of those with little toxic effect for normal cells. Although PPP treatment resulted in pronounced differences between the death of normal fibroblasts and metastatic melanoma cells, levels of cancer cell death were still well below $100 \%$. A complementary co-treatment was required to achieve this critical task. Normal human fibroblasts, including TIG-3, are known to have very low surface expression of TRAIL-R2/DR5 and TRAIL-R1/DR4, exhibiting high resistance to TRAIL (Fig. 6A). On the other hand, our previous studies demonstrated intermediate to high levels of surface expression of DR5 on many melanoma cells (Fig. 6A), while DR4 surface expression was, as a rule, very low or negligible in these cells [10]. Transformed human skin fibroblasts (HSF) demonstrated also intermediate levels of surface DR5 expression. However, most melanoma lines are relatively resistant to TRAIL alone and need additional sensitization through the blockage of cell survival pathways [8]. Interestingly, WM793 vertical-growth-phase and WM9 metastatic melanoma cells are sensitive to TRAIL treatment and exhibited a dose-dependent response for $10-100 \mathrm{ng} / \mathrm{ml}$ of TRAIL alone (Supplementary Fig. 1). We selected a dose of TRAIL (50 $\mathrm{ng} / \mathrm{ml}$ ) that could kill approximately $40 \%$ of these sensitive melanoma cells for further study in combined treatments.

Combined treatment of TRAIL ( $50 \mathrm{ng} / \mathrm{ml}$ ) and PPP, which has been used in the present study, resulted in a substantial increase in the levels of apoptosis for vertical-growth-phase WM793 and for metastatic WM9 melanoma cells, as measured by FACS analysis of sub-G1 levels. LU1205 metastatic melanoma cells with high levels of AKT activity and low sensitivity to TRAIL alone demonstrated a relatively modest increase in apoptotic levels after combined treatment with TRAIL and PPP. The early melanoma cells WM35 with low DR5 surface expression showed also limited sensitivity to TRAIL, while the primary fibroblasts IMR-90 showed virtually no sensitivity to either TRAIL or PPP (Fig. 6B with a typical experiment and Fig. 7A with data for 4 independent repeats of this experiment). A combination of TRAIL ( $50 \mathrm{ng} / \mathrm{ml}$ ) and a protein synthesis inhibitor, cycloheximide (CHX, $4 \mu \mathrm{M})$, also induced high levels of apoptosis in WM793 and WM9 cells, but intermediate levels in LU1205 cells. PPP co-treatment still modestly increased levels of TRAIL + CHX induced apoptosis for WM35 cells, but not for LU1205 cells (Fig. 7B). However, a substitution of LY294002, an efficient inhibitor of the PI3K-AKT pathway, for PPP dramatically increased the apoptosis induced by TRAIL + CHX in LU1205 cells (Figs. 7C and D), further highlighting a role for PI3K-AKT for suppression of TRAIL-induced apoptosis. Transformed HSF demonstrated increased apoptosis after treatment with a combination of TRAIL and PPP and, especially, TRAIL and CHX (Fig. 7). PPP was also able to accelerate FasL-induced apoptosis of melanoma cells, albeit less efficiently than TRAILinduced apoptosis (Fig. 6B).

Results of the proliferation assay further indicated that combined treatment by TRAIL ( $50 \mathrm{ng} / \mathrm{ml}$ and $25 \mathrm{ng} / \mathrm{ml}$ ) and PPP (250 nM) strongly suppressed WM793 and WM9 melanoma cell proliferation in culture demonstrating a high efficacy of such combined treatment for cancer cells with regulated PI3K-AKT activity (Fig. 8). We have used TIG3 normal human fibroblasts as the control line. PPP alone induced G2/M arrest of TIG3 fibroblasts without pronounced toxicity (see Fig. 3). These cells are relatively insensitive to TRAIL treatment and combined treatment of TRAIL and PPP had no additive effects. In contrast, WM793 cells, which are sensitive to TRAIL ( $50 \mathrm{ng} / \mathrm{ml}$ and $25 \mathrm{ng} / \mathrm{ml}$ ) and PPP (250 nM), demonstrated pronounced additive effects for combined treatment. For WM9 cells accelerated effects of combined treatment might be observed between day 1 and 3 for TRAIL dose at $25 \mathrm{ng} / \mathrm{ml}$ (Fig. 8).

The clonogenic survival assay confirmed the enhanced effectiveness of killing melanoma cells using combined treatment with TRAIL ( $50 \mathrm{ng} / \mathrm{ml}$ ) and PPP (250-500 nM) that was more effective compared to results of killing by TRAIL alone (Figs. 9A and B). More than $90 \%$ of WM9 and WM793 cells were killed by a combination of TRAIL and PPP (Fig. 9B). Surprisingly, nearly $80 \%$ of resistant LU1205 metastatic melanoma cells were also killed. This may indicate a mix of apoptotic and non-apoptotic death pathways induced by prolonged treatment of PPP and TRAIL in LU1205 cells. The early melanoma WM35 cells were quite resistant to killing by a combination of TRAIL + PPP, as well as by TRAIL + CHX (Fig. 9). It should also be highlighted that the optimal concentration of PPP $(0.5 \mu \mathrm{M})$ for treatment in combination with TRAIL was substantially lower than for CHX $(4 \mu \mathrm{M})$. Taken together, the results obtained in this study demonstrated a predictably variable apoptotic response of human melanoma cells to PPP, TRAIL and its combination. WM9 and WM793 cells were efficiently killed by a combined treatment, while LU1205 cells demonstrated a certain resistance to apoptosis, due to high basal AKT activity, which could be overcome by an additional inhibition of AKT activation. On the other hand, WM35 cells with a deficiency in IGF-1R expression also exhibited only a modest response to combined treatment.

\section{Discussion}

Metastatic melanoma is one of the most refractory cancers to treat. The main signaling pathways regulating cell survival, PI3KAKT, BRAF-MEK-ERK, IKK-NF- $K B$ and JAK2-STAT3, are highly active in metastatic melanoma cells, providing strong resistance to apoptotic signaling $[9,39]$. This activation is based on multiple genetic and epigenetic mechanisms, including activating mutations of NRAS [40], frequent deletion of PTEN, an endogenous inhibitor of the PI3K-AKT pathway [22], a mutation in BRAF (V600E) that permanently activates the downstream MAPK pathway [19,41], genomic amplification of IKBKB chromosome area [42] and additional epigenetic regulation of the IKK-NF-KB [43] and JAK2-STAT3 [44] pathways in human melanoma cells. During the last decade, tremendous efforts have been undertaken to create and investigate specific inhibitors of these pathways to block tumor growth. Multiple clinical trials with specific pharmacological inhibitors and antagonistic monoclonal antibodies are in progress now. However, the usage of inhibitors of the certain signaling pathway may results in the dramatic and undesirable induction of the bypass signaling pathway. Thus, RAF inhibitors are selective in inhibiting proliferation of $B R A F$ (V600E) cancer cell lines, but activate the MAPK pathway in non-BRAF (V600E) cells in CRAF-dependent manner. It could potentially induce CRAF in normal tissues and non-BRAF (V600E) tumors during treatment [45].

An alternative approach for the treatment of melanoma is based on the specific induction of apoptosis in cancer cells via death receptor-mediated pathways. Fortunately, many metastatic 

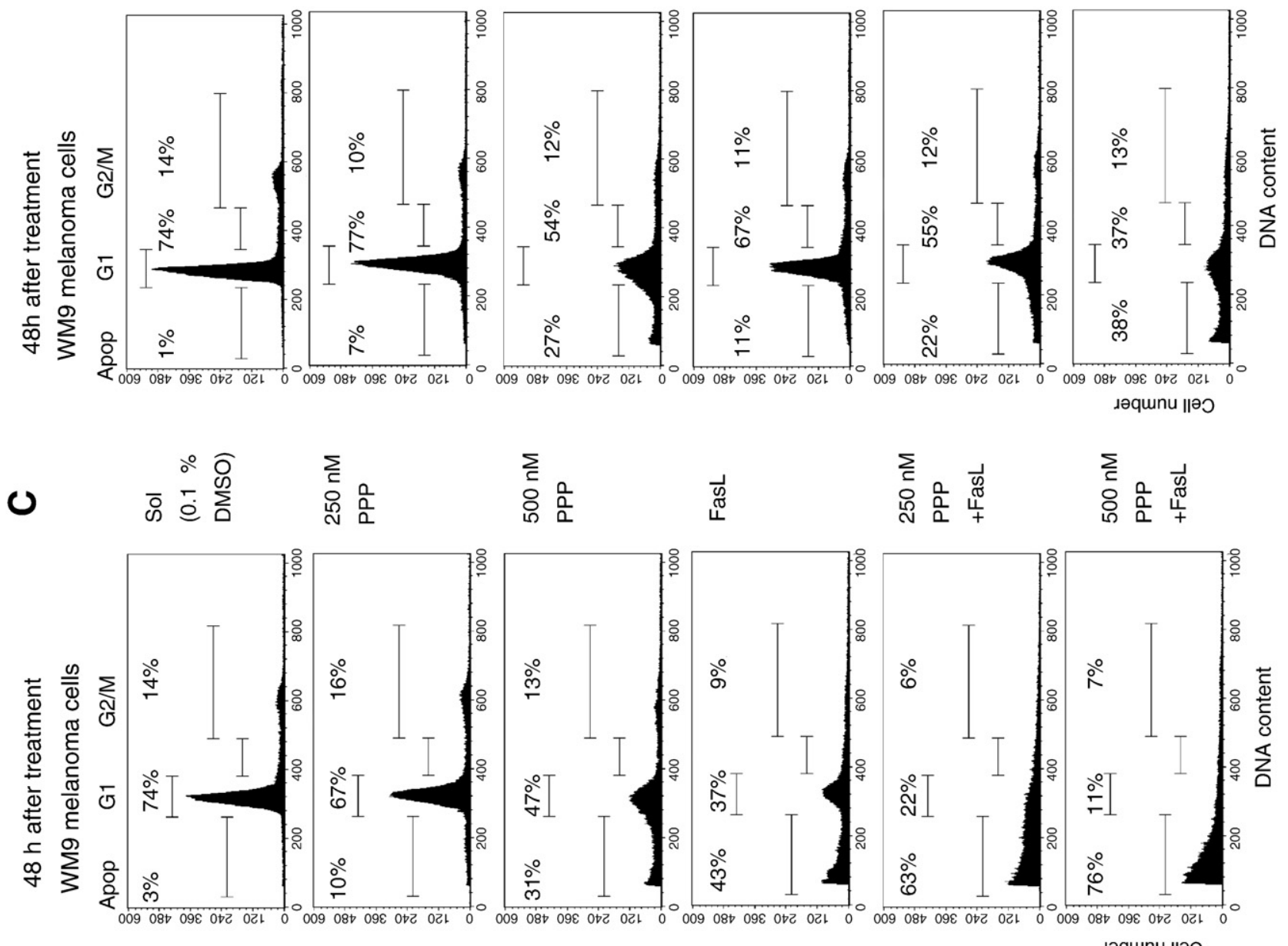
m

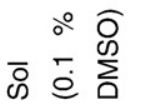

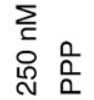
층
究竞
究高高章
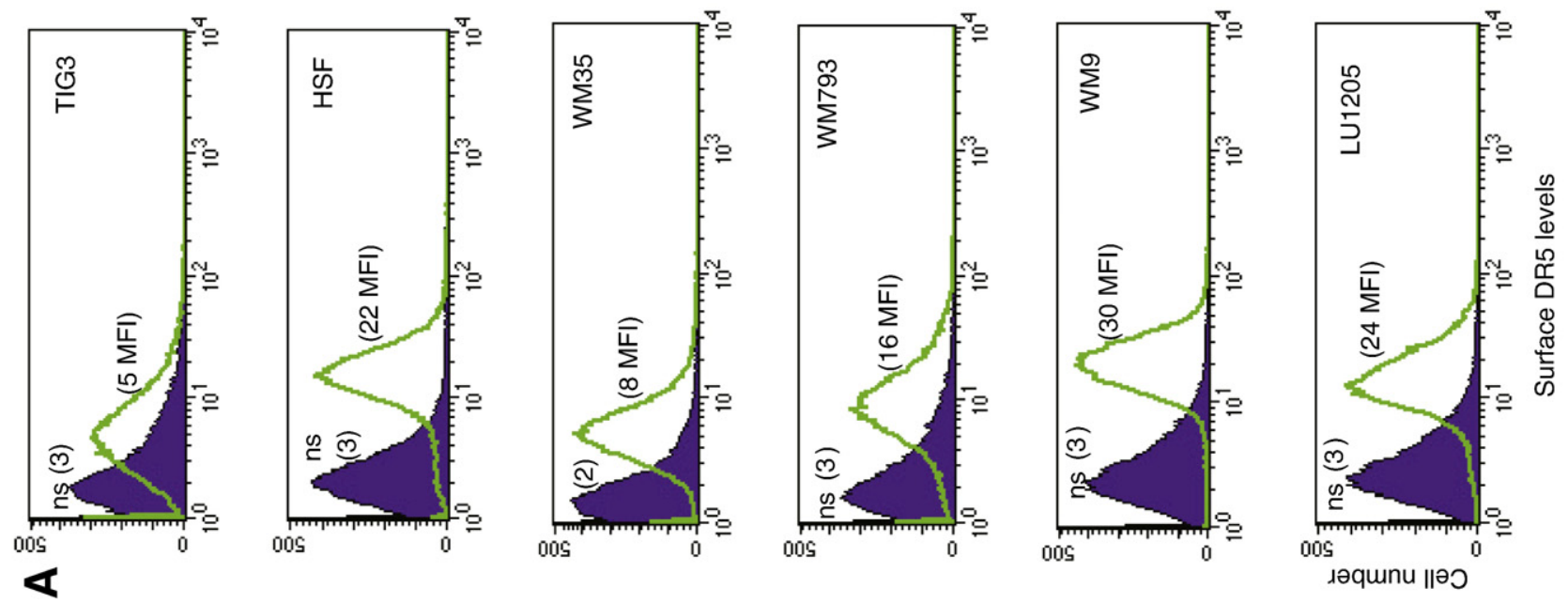
A

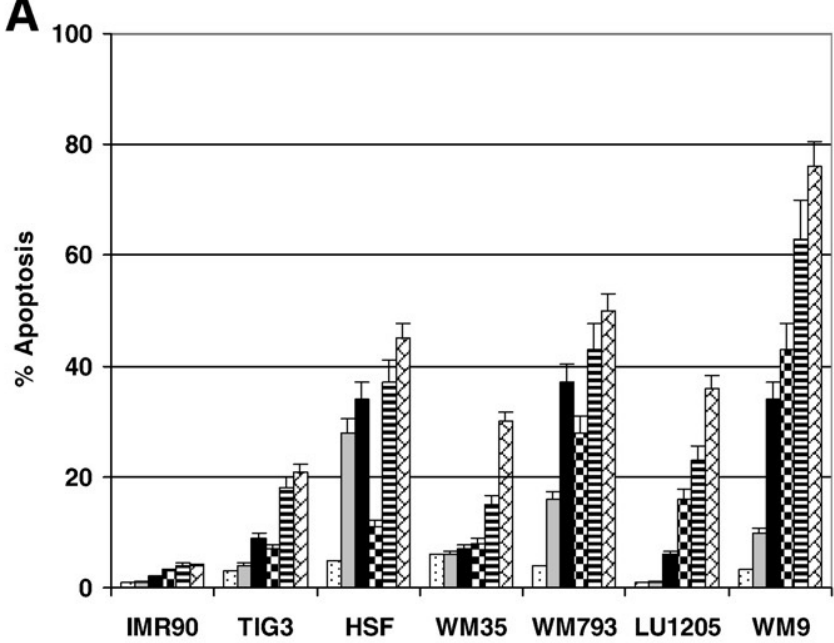

B

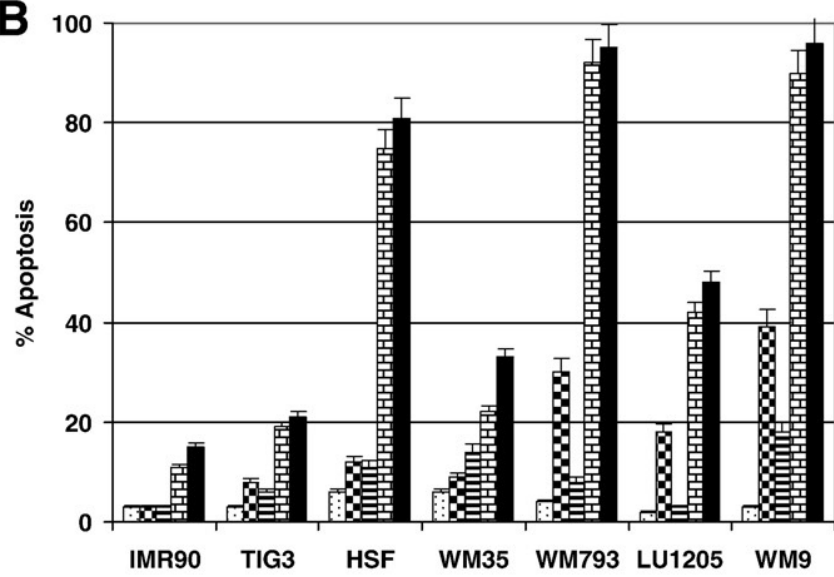

C

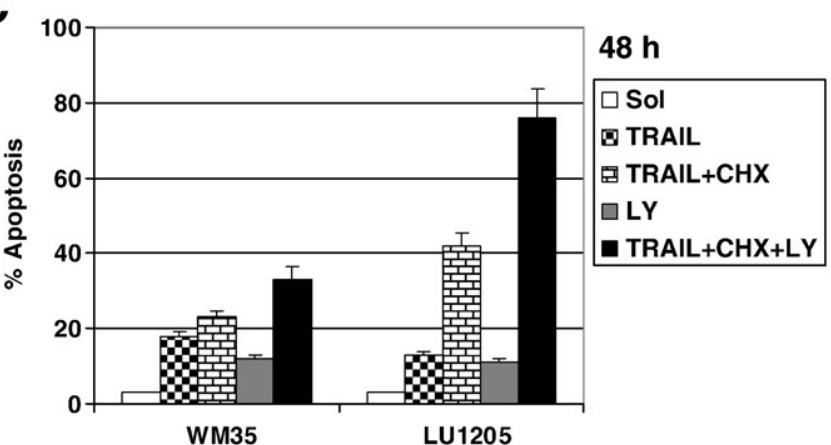

$48 \mathrm{~h}$

(5) Sol

$\square 250$ nM PPP

500 nM PPP

$\square$ TRAIL

I250 nM PPP+TRAIL

$\square 500 \mathrm{nM}$ PPP+TRAIL

\section{당 Sol \\ DTRAIL \\ E CHX \\ GTRAIL $+\mathrm{CHX}$ \\ - TRAIL+CHX+PPP}

D LU1205, $6 \mathrm{~h}$

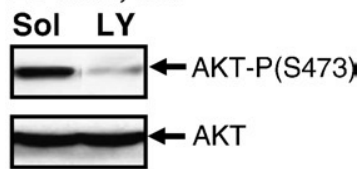

Fig. 7 - A, B and C. Apoptotic cell death after combined treatment with TRAIL + PPP, TRAIL + CHX, TRAIL + CHX + PPP or TRAIL + CHX + LY294002 in indicated normal and cancer (melanoma) cell lines. TRAIL (50 ng/ml), CHX (4 $\mu \mathrm{M})$ and LY294002 (50 $\mu \mathrm{M})$ and indicated doses of PPP were used with. Error bars represent mean \pm S.D. for four independent experiments (Student's $t$ test, $P<0.05$ ). D. Western blot analysis of active and total AKT levels in LU1205 cells $6 \mathrm{~h}$ after treatment with LY294002 (50 $\mu \mathrm{M})$.

melanomas exhibit the surface expression of TRAIL-R2/DR5, creating a possibility for therapy. However, to improve the clinical applicability, an additional treatment to block cancer cell survival functions is needed in order to substantially enhance TRAILmediated apoptosis in melanoma cells. We and others have previously used sodium arsenite [46], resveratrol [8], ATM inhibitors

Fig. 6 - TRAIL-mediated apoptotic signaling in human melanoma cells. A. Surface expression of TRAIL-R2/DR5 in indicated cell lines cells was determined by immunostaining using PE-labeled $\mathrm{mAb}$ and the FACS analysis. Medium fluorescent intensity (MFI) is indicated. B, C. Apoptosis in WM9 metastatic melanoma cells after treatment by PPP, TRAIL, FasL or combination ether PPP + TRAIL $(50 \mathrm{ng} / \mathrm{ml})$ or PPP + FasL $(50 \mathrm{ng} / \mathrm{ml})$. Results of a typical experiment are presented. Apoptosis (Apop) levels were determined as the percentage of cells with hypodiploid content of DNA in the pre-G0/G1 region using flow cytometry. 
TIG3
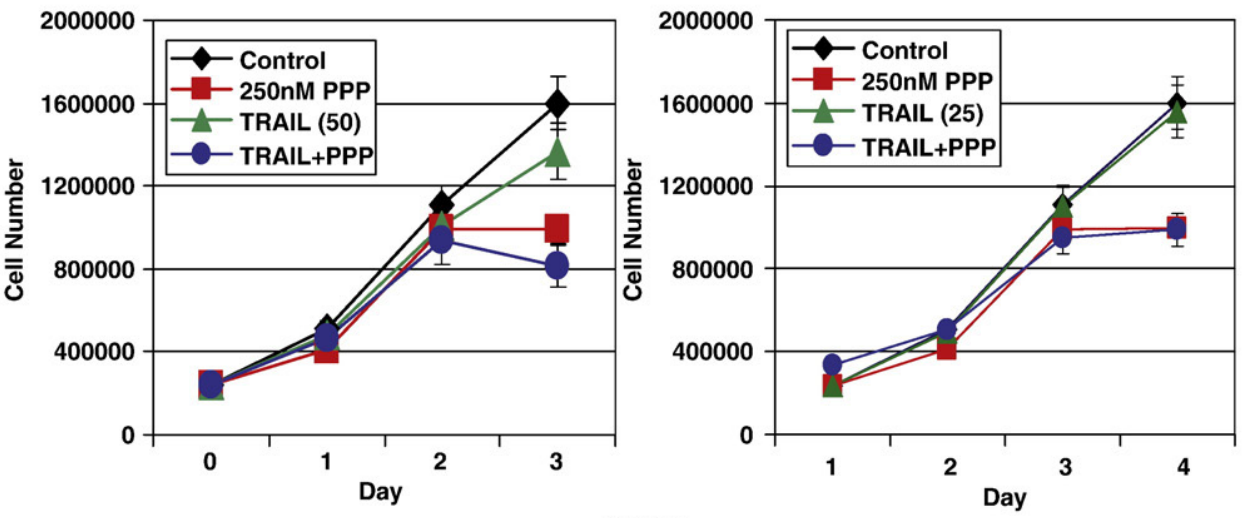

WM793
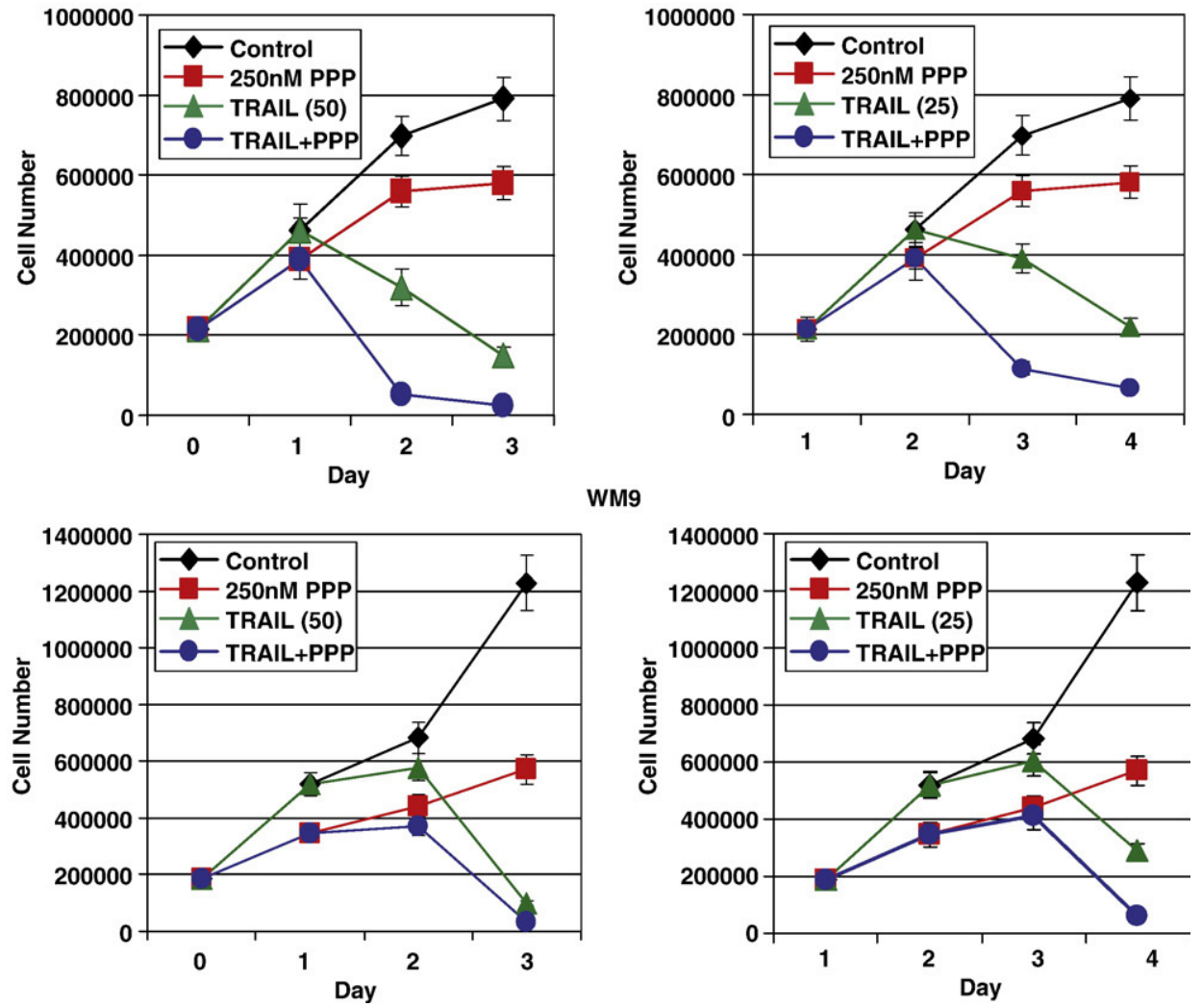

Fig. 8 - Dose-dependent effects of PPP (250-500 $\mathrm{nM}$ ) and TRAIL ( 25 and $50 \mathrm{ng} / \mathrm{ml}$ ) alone or in combination on the cell growth of TIG3 normal human fibroblasts and WM35 and WM9 melanoma cell lines. PPP was dissolved in DMSO; the final concentration of DMSO in the medium was $0.1 \%$. PPP was added to the cell media at day 0, TRAIL was added at day 1. Error bars represent mean \pm S.D. from three independent experiments (Student's $t$ test, $P<0.05$ ).

[10], IFN- $\beta$ [47], tunicamycin [48] and several other agents targeting cell surviving pathways [11] to sensitize melanoma cells to TRAILinduced apoptosis.

The main target of the approach used in the present study was IGF-1R-mediated signaling pathway that was specifically blocked by PPP before TRAIL action. Such inhibition could be an efficient way to suppress, partially or completely, the downstream PI3K-AKT and MAPK pathway, depending on the genotype of the cancer cell clones. We demonstrated in the present study that pre-treatment was especially efficient for melanoma lines with low or modest basal AKT activity (without PTEN inactivated mutation) and resulted in a strong up-regulation of TRAIL-mediated apoptosis after a combined treatment. In recent years, PPP treatment was successfully used for the induction of apoptosis in several cancer models [49,50]. While both PPP [51,52] and TRAIL [5,53] are still in early-stage clinical trials and much remains to be determined about their single-agent efficacy, our data suggest that combination therapy using these two drugs may prove to be a more effective approach. Whereas current melanoma therapies rely on broad-based cellular damage to induce cell death using both necrosis and apoptosis, these new approaches work through specific receptor-mediated signaling pathways, making them more able to preferentially target cancer 

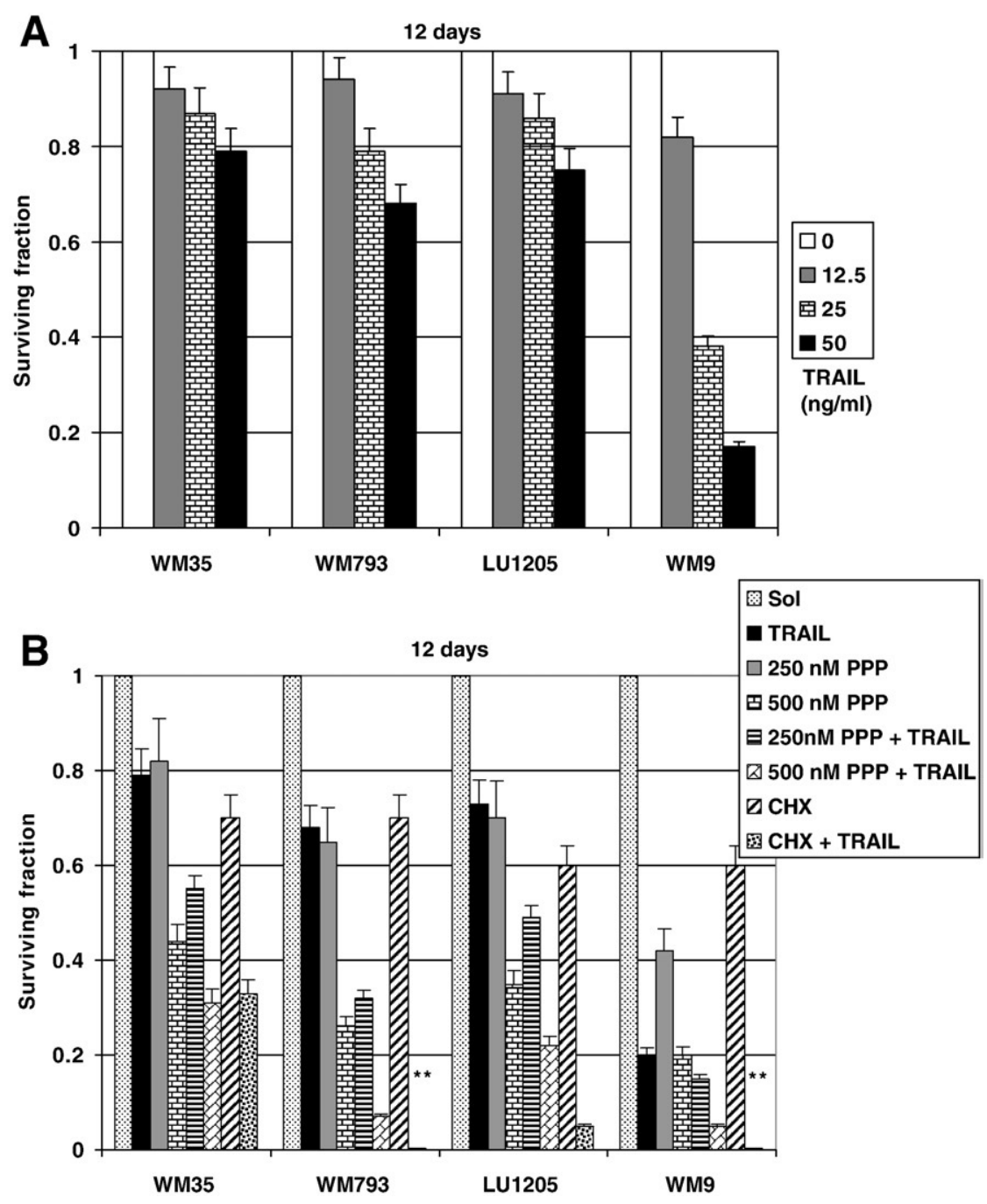

Fig. 9 - A. Clonogenic survival assay of indicated melanoma cell lines 12 days after treatment with different concentration of TRAIL alone. B. Clonogenic survival assay of indicated melanoma cell lines 12 days after indicated treatments with PPP, TRAIL (50 ng/ $\mathrm{ml})$, PPP + TRAIL, CHX ( $4 \mu \mathrm{M})$, CHX + TRAIL. Error bars represent mean \pm S.D. for three independent experiments (Student's $t$ test, $P<0.05$ ).

cells but also more vulnerable to intercellular genomic diversity. By both activating the extrinsic death pathway using TRAIL and disabling the IGF-1R-dependent survival pathways using PPP, we have substantially increased the therapeutic ratio of treatmentsensitive melanoma cells.

In addition to testing our current regimen, we also hoped to better understand the molecular mechanisms through which PPP works to discover other potential therapeutic targets. One critical observation was the confirmation of the connection of IGF-1Rmediated signaling with the activation of ATM [54], a significant regulator of radioresistance (Fig. 1B), as previously observed [39]. Treatment of human melanoma cells with PPP induced apoptotic signaling pathways and resulted in the cleavage and degradation of ATM that was accompanied by a substantially increased radiosensitivity in the metastatic melanoma cells (non-published observation). Cleavage and inactivation of ATM during TNF $\alpha$ induced apoptotic commitment was also previously reported [55]. Interestingly, in our recent paper we demonstrated a dramatic up- regulation of TRAIL-mediated apoptosis by inhibition of ATM [10]. Our current studies confirmed and expanded these observations by using a combination of recombinant TRAIL and the IGF-1R inhibitor PPP that also substantially up-regulated TRAIL-mediated apoptosis. While numerous barriers remain before we can suggest this specific regimen as a treatment, our progress thus far suggests that apoptosis-inducing melanoma treatments are a viable approach [10].

\section{Acknowledgments}

We would like to thank Drs. M. Herlyn and Z. Ronai for melanoma cell lines, Dr. H. Lieberman for critical reading manuscript and discussion. This work was supported by NIH Grants CA 49062 , ES 11804, Superfund Grant P42 ES 10349, and Environmental Center Grant P30 ES 09089. TBK was a recipient of NIH summer training grant. 


\section{Appendix A. Supplementary data}

Supplementary data associated with this article can be found, in the online version, at doi:10.1016/j.yexcr.2010.04.014.

\section{REFERENCES}

[1] K. Satyamoorthy, G. Li, M.R. Gerrero, M.S. Brose, P. Volpe, B.L. Weber, P. Van Belle, D.E. Elder, M. Herlyn, Constitutive mitogen-activated protein kinase activation in melanoma is mediated by both BRAF mutations and autocrine growth factor stimulation, Cancer Res. 63 (2003) 756-759.

[2] C. Perlis, M. Herlyn, Recent advances in melanoma biology, Oncologist 9 (2004) 182-187.

[3] J.C. Reed, Drug insight: cancer therapy strategies based on restoration of endogenous cell death mechanisms, Nat. Clin. Pract. Oncol. 3 (2006) 388-398.

[4] U. Schaefer, O. Voloshanenko, D. Willen, H. Walczak, TRAIL: a multifunctional cytokine, Front. Biosci. 12 (2007) 3813-3824.

[5] A. Ashkenazi, R.S. Herbst, To kill a tumor cell: the potential of proapoptotic receptor agonists, J. Clin. Investig. 118 (2008) 1979-1990.

[6] F.A. Greco, P. Bonomi, J. Crawford, K. Kelly, Y. Oh, W. Halpern, L. Lo, G. Gallant, J. Klein, Phase 2 study of mapatumumab, a fully human agonistic monoclonal antibody which targets and activates the TRAIL receptor- 1 , in patients with advanced non-small cell lung cancer, Lung Cancer 61 (2008) 82-90.

[7] S. Wang, The promise of cancer therapeutics targeting the TNF-related apoptosis-inducing ligand and TRAIL receptor pathway, Oncogene 27 (2008) 6207-6215.

[8] V.N. Ivanov, M.A. Partridge, G.E. Johnson, S.X. Huang, H. Zhou, T.K. Hei, Resveratrol sensitizes melanomas to TRAIL through modulation of antiapoptotic gene expression, Exp. Cell Res. 314 (2008) 1163-1176.

[9] V.N. Ivanov, A. Bhoumik, Z. Ronai, Death receptors and melanoma resistance to apoptosis, Oncogene 22 (2003) 3152-3161.

[10] V.N. Ivanov, H. Zhou, M.A. Partridge, T.K. Hei, Inhibition of ataxia telangiectasia mutated kinase activity enhances TRAIL-mediated apoptosis in human melanoma cells, Cancer Res. 69 (2009) 3510-3519.

[11] P. Hersey, X.D. Zhang, Treatment combinations targeting apoptosis to improve immunotherapy of melanoma, Cancer Immunol. Immunother. 58 (2009) 1749-1759.

[12] V.N. Ivanov, T.K. Hei, Arsenite sensitizes human melanomas to apoptosis via tumor necrosis factor alpha-mediated pathway, J. Biol. Chem. 279 (2004) 22747-22758.

[13] F. Meier, S. Busch, K. Lasithiotakis, D. Kulms, C. Garbe, E. Maczey, M. Herlyn, B. Schittek, Combined targeting of MAPK and AKT signalling pathways is a promising strategy for melanoma treatment, Br. J. Dermatol. 156 (2007) 1204-1213.

[14] M. Pollak, Insulin, insulin-like growth factors and neoplasia, Best Pract. Res. Clin. Endocrinol. Metab. 22 (2008) 625-638.

[15] M. Pollak, Insulin and insulin-like growth factor signalling in neoplasia, Nat. Rev. Cancer 8 (2008) 915-928.

[16] O. Larsson, A. Girnita, L. Girnita, Role of insulin-like growth factor 1 receptor signalling in cancer, Br. J. Cancer 92 (2005) 2097-2101.

[17] K. Satyamoorthy, G. Li, B. Vaidya, D. Patel, M. Herlyn, Insulin-like growth factor-1 induces survival and growth of biologically early melanoma cells through both the mitogen-activated protein kinase and beta-catenin pathways, Cancer Res. 61 (2001) 7318-7324.

[18] A. Girnita, C. All-Ericsson, M.A. Economou, K. Astrom, M. Axelson, S. Seregard, O. Larsson, L. Girnita, The insulin-like growth factor-I receptor inhibitor picropodophyllin causes tumor regression and attenuates mechanisms involved in invasion of uveal melanoma cells, Clin. Cancer Res. 12 (2006) 1383-1391.
[19] H. Davies, G.R. Bignell, C. Cox, P. Stephens, S. Edkins, S. Clegg, J. Teague, H. Woffendin, M.J. Garnett, W. Bottomley, N. Davis, E. Dicks, R. Ewing, Y. Floyd, K. Gray, S. Hall, R. Hawes, J. Hughes, V. Kosmidou, A. Menzies, C. Mould, A. Parker, C. Stevens, S. Watt, S. Hooper, R. Wilson, H. Jayatilake, B.A. Gusterson, C. Cooper, J. Shipley, D. Hargrave, K. Pritchard-Jones, N. Maitland, G. Chenevix-Trench, G.J. Riggins, D.D. Bigner, G. Palmieri, A. Cossu, A. Flanagan, A. Nicholson, J.W. Ho, S.Y. Leung, S.T. Yuen, B.L. Weber, H.F. Seigler, T.L. Darrow, H. Paterson, R. Marais, C.J. Marshall, R. Wooster, M.R. Stratton, P.A. Futreal, Mutations of the BRAF gene in human cancer, Nature 417 (2002) 949-954.

[20] L.J. van 't Veer, B.M. Burgering, R. Versteeg, A.J. Boot, D.J. Ruiter, S. Osanto, P.I. Schrier, J.L. Bos, N-ras mutations in human cutaneous melanoma from sun-exposed body sites, Mol. Cell. Biol. 9 (1989) 3114-3116.

[21] K.S. Smalley, M. Xiao, J. Villanueva, T.K. Nguyen, K.T. Flaherty, R. Letrero, P. Van Belle, D.E. Elder, Y. Wang, K.L. Nathanson, M Herlyn, CRAF inhibition induces apoptosis in melanoma cells with non-V600E BRAF mutations, Oncogene 28 (2009) 85-94.

[22] H. Wu, V. Goel, F.G. Haluska, PTEN signaling pathways in melanoma, Oncogene 22 (2003) 3113-3122.

[23] H. Tsao, V. Goel, H. Wu, G. Yang, F.G. Haluska, Genetic interaction between NRAS and BRAF mutations and PTEN/MMAC1 inactivation in melanoma, J. Invest. Dermatol. 122 (2004) 337-341.

[24] M. Resnicoff, D. Coppola, C. Sell, R. Rubin, S. Ferrone, R. Baserga, Growth inhibition of human melanoma cells in nude mice by antisense strategies to the type 1 insulin-like growth factor receptor, Cancer Res. 54 (1994) 4848-4850.

[25] J.S. Yuen, E. Akkaya, Y. Wang, M. Takiguchi, S. Peak, M. Sullivan, A.S. Protheroe, V.M. Macaulay, Validation of the type 1 insulin-like growth factor receptor as a therapeutic target in renal cancer, Mol. Cancer Ther. 8 (2009) 1448-1459.

[26] A. Girnita, L. Girnita, F. del Prete, A. Bartolazzi, O. Larsson, M. Axelson, Cyclolignans as inhibitors of the insulin-like growth factor-1 receptor and malignant cell growth, Cancer Res. 64 (2004) 236-242.

[27] E.K. Maloney, J.L. McLaughlin, N.E. Dagdigian, L.M. Garrett, K.M. Connors, X.M. Zhou, W.A. Blattler, T. Chittenden, R. Singh, An anti-insulin-like growth factor I receptor antibody that is a potent inhibitor of cancer cell proliferation, Cancer Res. 63 (2003) 5073-5083.

[28] D. Yee, Targeting insulin-like growth factor pathways, Br. J. Cancer 94 (2006) 465-468.

[29] J. Riedemann, V.M. Macaulay, IGF1R signalling and its inhibition, Endocrinol. Relat. Cancer 13 (2006) S33-S43 Suppl 1.

[30] B. Sehat, A. Tofigh, Y. Lin, E. Trocme, U. Liljedahl, J. Lagergren, O. Larsson, SUMOylation Mediates the Nuclear Translocation and Signaling of the IGF-1 Receptor, Sci Signal 3 ra10.

[31] C. Hilmi, L. Larribere, S. Giuliano, K. Bille, J.P. Ortonne, R. Ballotti, C. Bertolotto, IGF1 promotes resistance to apoptosis in melanoma cells through an increased expression of BCL2, BCL-X(L), and survivin, J. Investig. Dermatol. 128 (2008) 1499-1505.

[32] M. Krasilnikov, V.N. Ivanov, J. Dong, Z. Ronai, ERK and PI3K negatively regulate STAT-transcriptional activities in human melanoma cells: implications towards sensitization to apoptosis, Oncogene 22 (2003) 4092-4101.

[33] N.K. Haass, K. Sproesser, T.K. Nguyen, R. Contractor, C.A. Medina, K.L. Nathanson, M. Herlyn, K.S. Smalley, The mitogen-activated protein/extracellular signal-regulated kinase kinase inhibitor AZD6244 (ARRY-142886) induces growth arrest in melanoma cells and tumor regression when combined with docetaxel, Clin. Cancer Res. 14 (2008) 230-239.

[34] K.S. Smalley, M. Lioni, M. Dalla Palma, M. Xiao, B. Desai, S. Egyhazi, J. Hansson, H. Wu, A.J. King, P. Van Belle, D.E. Elder, K.T. Flaherty, M. Herlyn, K.L. Nathanson, Increased cyclin D1 expression can mediate BRAF inhibitor resistance in BRAF V600E-mutated melanomas, Mol. Cancer Ther. 7 (2008) 2876-2883.

[35] J.M. Stahl, A. Sharma, M. Cheung, M. Zimmerman, J.Q. Cheng, M.W. Bosenberg, M. Kester, L. Sandirasegarane, G.P. Robertson, 
Deregulated Akt3 activity promotes development of malignant melanoma, Cancer Res. 64 (2004) 7002-7010.

[36] K. Satyamoorthy, E. DeJesus, A.J. Linnenbach, B. Kraj, D.L. Kornreich, S. Rendle, D.E. Elder, M. Herlyn, Melanoma cell lines from different stages of progression and their biological and molecular analyses, Melanoma Res. 7 (Suppl 2) (1997) S35-S42.

[37] P. Lopez-Bergami, H. Kim, A. Dewing, J. Goydos, S. Aaronson, Z. Ronai, c-Jun regulates phosphoinositide-dependent kinase 1 transcription: implication for Akt and protein kinase $\mathrm{C}$ activities and melanoma tumorigenesis, J. Biol. Chem. 285 (2010) 903-913.

[38] R. Vasilcanu, D. Vasilcanu, L. Rosengren, N. Natalishvili, B. Sehat, S. Yin, A. Girnita, M. Axelson, L. Girnita, O. Larsson, Picropodophyllin induces downregulation of the insulin-like growth factor 1 receptor: potential mechanistic involvement of Mdm2 and beta-arrestin1, Oncogene 27 (2008) 1629-1638.

[39] L. Chin, L.A. Garraway, D.E. Fisher, Malignant melanoma: genetics and therapeutics in the genomic era, Genes Dev. 20 (2006) 2149-2182.

[40] A. van Elsas, S.F. Zerp, S. van der Flier, K.M. Kruse, C. Aarnoudse, N.K. Hayward, D.J. Ruiter, P.I. Schrier, Relevance of ultraviolet-induced $\mathrm{N}$-ras oncogene point mutations in development of primary human cutaneous melanoma, Am. J. Pathol. 149 (1996) 883-893.

[41] D.A. Tuveson, B.L. Weber, M. Herlyn, BRAF as a potential therapeutic target in melanoma and other malignancies, Cancer Cell 4 (2003) 95-98.

[42] R. Beroukhim, C.H. Mermel, D. Porter, G. Wei, S. Raychaudhuri, J. Donovan, J. Barretina, J.S. Boehm, J. Dobson, M. Urashima, K.T. Mc Henry, R.M. Pinchback, A.H. Ligon, Y.J. Cho, L. Haery, H. Greulich, M. Reich, W. Winckler, M.S. Lawrence, B.A. Weir, K.E. Tanaka, D.Y. Chiang, A.J. Bass, A. Loo, C. Hoffman, J. Prensner, T. Liefeld, Q. Gao, D. Yecies, S. Signoretti, E. Maher, F.J. Kaye, H. Sasaki, J.E. Tepper, J.A. Fletcher, J. Tabernero, J. Baselga, M.S. Tsao, F. Demichelis, M.A. Rubin, P.A. Janne, M.J. Daly, C. Nucera, R.L. Levine, B.L. Ebert, S. Gabriel, A.K. Rustgi, C.R. Antonescu, M. Ladanyi, A. Letai, L.A. Garraway, M. Loda, D.G. Beer, L.D. True, A. Okamoto, S.L. Pomeroy, S. Singer, T.R. Golub, E.S. Lander, G. Getz, W.R. Sellers, M. Meyerson, The landscape of somatic copy-number alteration across human cancers, Nature 463 (2010) 899-905.

[43] M. Karin, Nuclear factor-kappaB in cancer development and progression, Nature 441 (2006) 431-436.

[44] T. Gritsko, A. Williams, J. Turkson, S. Kaneko, T. Bowman, M. Huang, S. Nam, I. Eweis, N. Diaz, D. Sullivan, S. Yoder, S. Enkemann, S. Eschrich, J.H. Lee, C.A. Beam, J. Cheng, S. Minton, C.A. Muro-Cacho, R. Jove, Persistent activation of stat3 signaling induces survivin gene expression and confers resistance to apoptosis in human breast cancer cells, Clin. Cancer Res. 12 (2006) 11-19.

[45] G. Hatzivassiliou, K. Song, I. Yen, B.J. Brandhuber, D.J. Anderson, R. Alvarado, M.J. Ludlam, D. Stokoe, S.L. Gloor, G. Vigers, T. Morales, I. Aliagas, B. Liu, S. Sideris, K.P. Hoeflich, B.S. Jaiswal, S. Seshagiri, H. Koeppen, M. Belvin, L.S. Friedman, S. Malek, RAF inhibitors prime wild-type RAF to activate the MAPK pathway and enhance growth, Nature.

[46] V.N. Ivanov, T.K. Hei, Sodium arsenite accelerates TRAIL-mediated apoptosis in melanoma cells through upregulation of TRAIL-R1/R2 surface levels and downregulation of cFLIP expression, Exp. Cell Res. 312 (2006) 4120-4138.

[47] M. Chawla-Sarkar, D.W. Leaman, B.S. Jacobs, E.C. Borden, IFN-beta pretreatment sensitizes human melanoma cells to TRAIL/Apo2 ligand-induced apoptosis, J. Immunol. 169 (2002) 847-855.

[48] T. Shiraishi, T. Yoshida, S. Nakata, M. Horinaka, M. Wakada, Y. Mizutani, T. Miki, T. Sakai, Tunicamycin enhances tumor necrosis factor-related apoptosis-inducing ligand-induced apoptosis in human prostate cancer cells, Cancer Res. 65 (2005) 6364-6370.

[49] E. Menu, H. Jernberg-Wiklund, T. Stromberg, H. De Raeve, L. Girnita, O. Larsson, M. Axelson, K. Asosingh, K. Nilsson, B. Van Camp, K. Vanderkerken, Inhibiting the IGF-1 receptor tyrosine kinase with the cyclolignan PPP: an in vitro and in vivo study in the 5T33MM mouse model, Blood 107 (2006) 655-660.

[50] S.B. Catrina, M. Lewitt, C. Massambu, A. Dricu, J. Grunler, M. Axelson, P. Biberfeld, K. Brismar, Insulin-like growth factor-I receptor activity is essential for Kaposi's sarcoma growth and survival, Br. J. Cancer 92 (2005) 1467-1474.

[51] D. Sachdev, D. Yee, Disrupting insulin-like growth factor signaling as a potential cancer therapy, Mol. Cancer Ther. 6 (2007) 1-12.

[52] T. Stromberg, S. Ekman, L. Girnita, L.Y. Dimberg, O. Larsson, M. Axelson, J. Lennartsson, U. Hellman, K. Carlson, A. Osterborg, K. Vanderkerken, K. Nilsson, H. Jernberg-Wiklund, IGF-1 receptor tyrosine kinase inhibition by the cyclolignan PPP induces G2/M-phase accumulation and apoptosis in multiple myeloma cells, Blood 107 (2006) 669-678.

[53] A. Ashkenazi, P. Holland, S.G. Eckhardt, Ligand-based targeting of apoptosis in cancer: the potential of recombinant human apoptosis ligand 2 /Tumor necrosis factor-related apoptosis-inducing ligand (rhApo2L/TRAIL), J. Clin. Oncol. 26 (2008) 3621-3630.

[54] Y. Shiloh, The ATM-mediated DNA-damage response: taking shape, Trends Biochem. Sci. 31 (2006) 402-410.

[55] G.C. Smith, F. d'Adda di Fagagna, N.D. Lakin, S.P. Jackson, Cleavage and inactivation of ATM during apoptosis, Mol. Cell. Biol. 19 (1999) 6076-6084. 